\title{
Ants Can Add Up Using Learned Numeric Symbols
}

\author{
Marie-Claire Cammaerts ${ }^{1} \&$ Roger Cammaerts ${ }^{1}$ \\ ${ }^{1}$ Independent researcher, retired from the Biology of Organisms Department, University of Brussels, Belgium. \\ ${ }^{2}$ Independent researcher, retired from the Natural and Agricultural Environmental Studies Department (DEMNA) \\ of the Walloon Region, Belgium. \\ Correspondence: Marie-Claire Cammaerts, independent researcher, 27, Square du Castel Fleuri, 1170 Bruxelles, \\ Belgium, tel: 32267349 69; Email addresses: mccammaerts@gmail.com
}

Received: July 4, 2020

doi:10.5539/ijb.v12n3p27
Accepted: August 13, 2020

Online Published: August 31, 2020

URL: doi: 10.5539/ijb.v12n3p27

\begin{abstract}
The workers of the ant Myrmica sabuleti have been shown to be able to add numbers of elements after having seen them simultaneously, side by side, during training, and to be able to acquire single as well as multiple symbolism. It was here examined if these ants could make additions using learned symbols. In fact, after having learned the required symbols during a first conditioning, the ants could, thanks to a second conditioning, carry out operations 1 $+1,1+2,2+2$ and $3+1$ by using the quantities of elements presented as well as their corresponding symbols. This ability results from the ants' learning of the correspondence between symbols and numbers of elements by an operative conditioning, and from their ability to add up two quantities viewed simultaneously. A comparison of the ants' score when adding elements and when adding their corresponding symbols suggests that the use of symbolism may represent some facility for the execution of simple arithmetic operations, as is the case in higher animal species.
\end{abstract}

Keywords: Counting, Myrmica sabuleti, numerosity ability, operative conditioning, symbolism

\section{Introduction}

In the course of our study on the ants' numerosity ability, we have shown among others that workers of the ant Myrmica sabuleti Meinert, 1861 can add numbers of elements when they saw them together, at once, during training (Cammaerts \& Cammaerts, 2019a), and can also associate a symbol with a number of elements, at least for the numbers 1 to 4 (Cammaerts \& Cammaerts, 2020b). We then wondered if these ants could add up using no longer numbers of elements presented side by side, but their corresponding symbols also presented side by side. Using four colonies of $M$. sabuleti, we experimentally examined if their workers could make, using symbols, the additions $1+1,1+2,2+2$, and $3+1$. Before relating our work, we here below summarize what has already been done in the field of numerical ability in vertebrates and invertebrates.

Many works have been done on animals' ability in counting, adding or subtracting numbers of elements. Several ones have been done on the animals' acquisition of numerical symbolism. Fewer studies were done on the animals' ability in adding or subtracting amounts using numeric symbols.

Vertebrates have been proved to be able to discriminate small numbers of elements, without precisely counting them, i.e. by a subitizing process. Fishes could distinguish 1 to 4 elements: Agrillo, Dadda, Serena, \& Bisazza, 2008; Stancher, Sovrano, Potrich, \& Vallortigara, 2013; salamanders, 1 - 4 elements: Uller, Jaeger, Guidry, \& Martin, 2003; frogs, 1 - 4 elements: Stancher, Rugani, Regolin, \& Vallortigara, 2015; rats, $1-3$ elements: Cox \& Montrose, 2016; wolves, 1 - 4 elements: Range, Jenikejew, Schröder, \& Virányi, 2014; capuchin monkeys, 1 5 elements: Addessi, Crescimbene, \& Visalberghi, 2008; chimpanzees, 1 - 7 elements: Murofushi, 1997). A more precise counting ability was shown in some frogs (up to 16 calls: Rose, 2017) and birds (up to 12 items: Hunt, Low, \& Burns, 2008; up to 16 items: Garland, Low, \& Burns, 2012). Some invertebrates were also shown to discriminate quantities: spiders: 3 distinct quantities (Rodriguez, Briceño, Briceño-Aguilar, \& Höbel, 2015) or 1 2 and more elements (Cross \& Jackson, 2017) and the insect Tenebrio molitor (1 - 4 items: Carazo, Font, Forteza-Behrendt, \& Desfilis, 2009; Carazo, Fernandez-Perea, \& Font, 2012). Higher quantities could be discriminated, but being impacted by a numerical distance effect (in salamanders: Krusche, Uller, \& Dicke, 2010; in birds: Tornick, Callahan, \& Gibson, 2015). Honeybees use the counting of up to 4 landmarks for navigating (Dacke \& Srinivasan, 2008), can be learned to differentiate under appetitive conditioning 2 and 4 elements from 3 
(Gross, Pahl, Si, Zhu, Tautz, \& Zhang, 2009; Bortot et al., 2019), can spontaneously discriminate between 1 and a quantity distant by $>3$ numerosities (Howard et al., 2020), and can be learned by appetitive-aversive conditioning to discriminate between 4 and up to 8 elements (Howard, Avarguès-Weber, Garcia, Greentree, \& Dyer, 2019d). Ants can discriminate $1-4$ elements (Cammaerts, 2008) and even up to 7 successive elements differing by one unit, but with a decreasing discriminating accuracy as the number of elements increases (Cammaerts R. \& Cammaerts, M.-C., 2020).

Some studies on number quantity estimation by animals were controlled for extraneous variables, so that only the numbers of counted items were concerned, not the non-numerical characteristics of the cues such as their color, size, shape and location. This was done for fishes ( $2-3$ elements: Agrillo, Dadda, Serena, \& Bisazza, 2009), crows (testing some of 1 to 30 elements for numerical distance effect: Ditz \& Nieder, 2016), for an elephant, $1-10$ elements (Irie, Haraiwa-Hasegawa, \& Kutsukake, 2019), for rhesus monkeys (1 - 5 elements: Nieder, Freedman, \& Miller, 2002; 1 - 9 elements: Brannon \& Terrace, 1998, 2000; Jordan \& Brannon, 2006; 1 - 9 elements extended to some larger numbers, up to 30: Cantlon \& Brannon, 2006), for chimpanzees (1 - 7 elements: Murofushi, 1997, Tomonaga, 2008), gorillas and orangutans (2 - 10 elements: Gazes et al., 2017). Control for extraneous variables was also made in the above-cited studies on honeybee number discrimination. As for ants, the numerical discrimination ability of M. sabuleti workers was shown to be slightly, not significantly, impacted by changes in the non-numeral characteristics of the elements (Cammaerts \& Cammaerts, 2020a). Taking account of the strength of this impact and of the ants' adding competence, it can be inferred, according to Gelman and Gallistel's (1978) definition of counting ability, that the $M$. sabuleti workers' numerical competence reaches the cardinality stage, but not that of abstraction.

Adding or subtracting numbers of elements is an ability rudimentarily developed in newborn chicks (Rugani, Fontinari, Simoni, Regolin, \& Villortigara, 2009) and in dogs (West \& Young, 2002), but clearly more developed in adult birds (Brannon, Wusthoff, Gallistel, \& Gibbon, 2001; Garland \& Low, 2014), in rhesus and snow monkeys (Hauser, MacNeilage, \& Ware, 1996; Flombaum, Junge, \& Hauser, 2005; Okuyama, Kuki, \& Mushiake, 2015) and in the chimpanzee (Rumbaugh, Savage-Rumbaugh, \& Hegel, 1987). Honeybees have been proved to be able to add and subtract 1 element from 1 to 5 others (Howard, Avarguès-Weber, Garcia, Greentree, \& Dyer, 2019a, b). The workers of the ant $M$. sabuleti have been proven to be able to add 1 element to 1 to 3 others and 2 elements to 3 elements as well as to subtract 1 element from 2 to 5 others if they clearly see the result of the operation during training (Cammaerts \& Cammaerts, 2019a, b, c). It is possible that training ants with two numbers of elements presented side by side allows them to mentally construct a single numerical image from these two numerosities sighted simultaneously.

Associating symbols with numbers is a skill observed so far in pigeons (Xia, Siemann, \& Delius, 2000), in a grey parrot (Pepperberg, 2006b), in rhesus monkeys (Washburn \& Rumbauch, 1991; Diester \& Nieder, 2007), in rhesus and capuchin monkeys (Beran et al., 2008) and in chimpanzees (Murofushi, 1997; Matsuzawa, 1985, 2009; Biro \& Matsuzawa, 2001, Beran, 2004). However, bees can also acquire numerical symbolism: they can associate shapes not evoking numerosities with a given number of elements ( 2 or 3 elements) (Howard, Avarguès-Weber, Garcia, Greentree, \& Dyer, 2019c). As for the ant M. sabuleti, we have shown that they can acquire single (Cammaerts \& Cammaerts, 2020b) as well as multiple numerical symbolisms (Cammaerts \& Cammaerts, 2020c).

A step further is the capability of making arithmetic operations by using symbols corresponding to numbers of elements. It was obtained in pigeons (summation of pairs of $1-9$ symbols: Olthof \& Roberts, 2000), in a grey parrot (summation of 0 - 6 Arabic numerals: Pepperberg, 2006a, 2012), in squirrel monkeys (summation of some Arabic numbers between 0 and 9: Olthof, Iden, \& Roberts, 1997) and in chimpanzees, making summation using Arabic numerals 0 to 4 (Boysen \& Berntson, 1989). The honeybee has also been shown to master numerical symbolism. It can be learned to associate a symbol such as a given color with an addition or a subtraction to be made (Howard et al., 2019a, b).

According to what is known about numerical ability in the ant $M$. sabuleti, it is time to examine if these insects have the capability of making additions using symbols previously learned. This will be made in two steps. The first one will be the learning of the correspondence between numbers of elements and symbols. The second step will be that of suggesting an addition by presenting to the ants, during training, side by side, two numbers of elements as well as their two symbols, since $M$. sabuleti workers only succeed in adding the terms of an addition when they see these terms simultaneously during training (Cammaerts \& Cammaerts, 2019a, b). We used an experimental protocol partly similar to those previously used for examining if the workers of $M$. sabuleti could acquire single then multiple symbolism. Some descriptions of the experimental material and methods are thus shortened. 


\section{Material and Methods}

\subsection{Collection and Maintenance of Ants}

The experiments were conducted on four colonies of M. sabuleti collected in September 2019 in an abandoned quarry located at Olloy/Viroin in Ardenne (Belgium). These colonies nested under stones and in grass. They contained about 500 workers, a queen and brood. Each colony was maintained in the laboratory in one to three glass tubes half filled with water, a cotton plug separating the ants from the water. The nest tubes of each colony were deposited in a tray $(34 \mathrm{~cm} \times 23 \mathrm{~cm} \times 4 \mathrm{~cm})$ that served as a foraging area, the borders of which having been slightly covered with talc to prevent ants from escaping. In this foraging area, pieces of Tenebrio molitor larvae (Linnaeus, 1758) were deposited three times per week on a glass piece, and a 30\% aqueous sugar solution was provided ad libitum in a cotton plugged tube. While working on ants, the lighting was ca 330 lux. The ambient temperature was permanently $c a 20^{\circ} \mathrm{C}$, the humidity $c a 80 \%$, and the electromagnetism $2 \mu \mathrm{Wm}^{2}$. These environmental conditions were appropriate for the species.

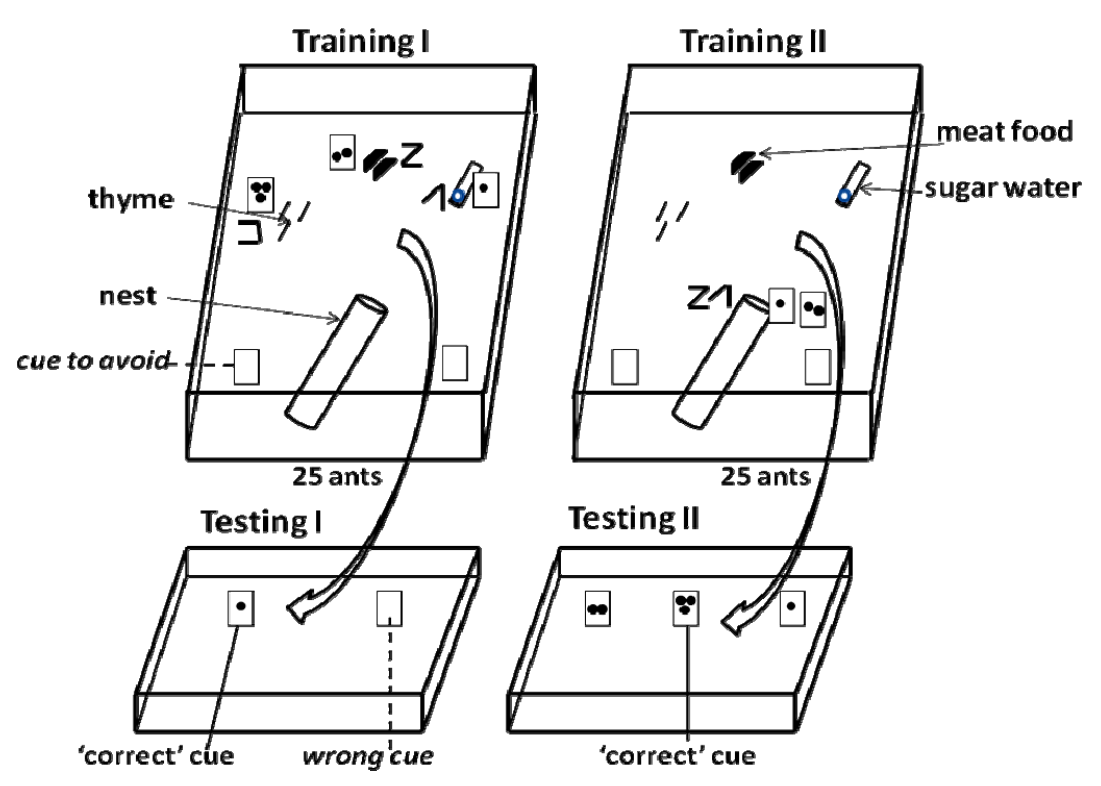

Figure 1. Experimental design for examining the ability of ants to add numbers using symbols

The here schematized addition is $1+2=3$. The ants were conditioned to three symbols and their corresponding numbers (Training I) and tested for checking their learning (Testing I). Just after, they were trained to two learned numbers set aside and to their two corresponding symbols also set aside, each pair at the nest entrance (Training II) and were tested to check if they correctly added the two numbers and the two symbols. Photos are shown in Figure

3, all the used cues being schematized in Figure 2. Details are given in the text.

\subsection{Training and Testing the Ants}

These processes are schematized in Figure 1 and can be seen in Figure 3. The ants were trained in their foraging area, and tested in a separate tray all along their continuous training period, two to three tests among the eight or eleven to be done (see Table 1) being made each day.

During a first training period devoted to the learning of symbols, the ants were provided with pairs of cues set near a reward, one cue set on the left and the other cue set on the right of the reward (see Figure 1, training I). One pair was located near their meat food, one pair was located near their sugar water tube and moreover, for colonies B and $\mathrm{D}$, one pair was located near pieces of thyme. One of the cues of each pair showed a number of black circles; the other cue was a symbol corresponding to that number of circles. Far from the nest entrance and from any reward, two other cues, each showing 5 black circles were placed at distance of each other. These last cues were those not to be memorized while the cues near the rewards were the ones to be memorized. During a second training period in which an addition was suggested to the ants, the latter were provided with four cues aside their nest entrance: two cues were numbers of circles placed side by side, the two other cues were the symbols corresponding to these numbers, also placed side by side (see Figure 1, training II). The ants were expected to add up the two presented numbers; they were also expected to add up the two presented symbols. During the first as well as the second training period, the ants moving or staying in the vicinity of all the presented cues were counted 32 times, and the 
mean of these counts were established. These means are given in the text and did not require statistical analysis, being only intended to show that enough ants saw the presented cues.

The ants were tested in a separate tray $(21 \mathrm{~cm} \times 15 \mathrm{~cm} \times 7 \mathrm{~cm})$, the borders of which were slightly covered with talc to prevent ants from escaping, and in which two (Testing I) or three (Testing II) cues had been set at about $8 \mathrm{~cm}$ or $6 \mathrm{~cm}$ from one another These cues are defined in the following subsection ('Cues presented to ants'). To make a test, 25 foragers of the experimented colony (A, B, C or D) were transferred into the tray devoted to testing, in front of the two or three cues. The left or right location of the cues was randomized. The tested ants walked in the tray and freely approached each of the cues. The numbers of them approaching each kind of cue at less than $2 \mathrm{~cm}$ were counted 20 times (i.e. at every 30 seconds) over 10 experimental minutes. These counts allowed calculating the proportion of ants responding to each cue; these proportions are given in the text only. The twenty numbers of ants chronologically obtained for each cue were summed by four, and the five sums of numbers obtained for each cue were compared to one another using the non-parametric matched-pairs signed-ranks test of Wilcoxon, reading the critical P value in Siegel \& Castellan's (1988) Table H for small sample sizes. The five sums of numbers obtained for each cue and the statistical results are given in Table 1. A one-tailed test was used when the comparisons concerned the result of conditioning (Testing I). A two-tailed test was used when the comparison involved 1 to 4 circles and their symbols, the ants having been conditioned to each of these kinds of cues (Testing II). After each test, the ants were set back into their foraging area, near their nest entrance.

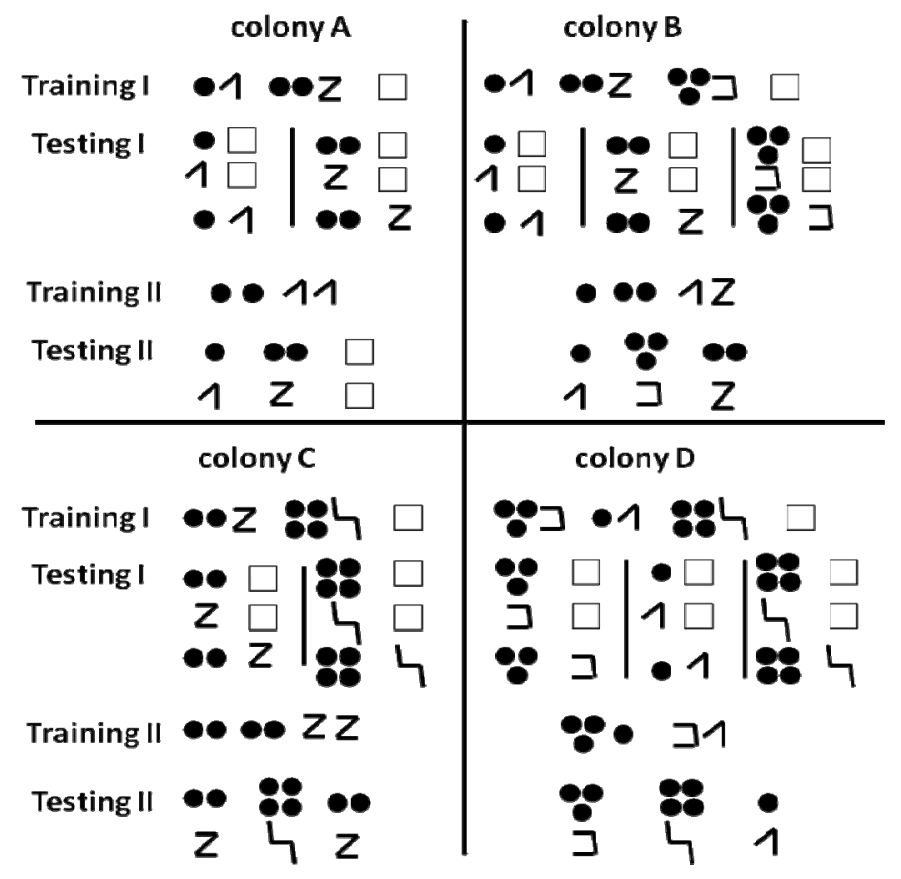

Figure 2. Cues presented to the ants for learning them numerical symbols (training and testing I), then for examining if they could use the learned symbols for making additions (training and testing II).

The places where the cues were located are shown in Figure 1; the experimental protocol is detailed in the text. Photos arranged as in this figure 2 can be seen in Figure 3.

\subsection{Cues Presented to Ants}

Each cue represented a number of circles or a symbol corresponding to that number. Each one was drawn inside of a square $2 \mathrm{~cm} \times 2 \mathrm{~cm}$ using a PC and software Word $\AA$, and printed. Each square was cut then tied on the front vertical face $(2 \mathrm{~cm} \times 2 \mathrm{~cm})$ of a stand made of strong white paper $\left(\right.$ Steinbach $\left.{ }^{\circledR}\right)$ and maintained vertically thanks to a duly folded horizontal part [ $2 \times(1 \mathrm{~cm} \times 0.5 \mathrm{~cm})]$

The presented cues are schematized in Figure 2 and photos of some of them are shown in Figure 3. Here below, we detailed them, colony by colony, defining successively the cues used during the first training and testing sessions, then those used during the second training and testing sessions. This enumeration serves as an explanation of the experimental schedule. Colonies A, B, C, and D were tested for their ability in making the additions $1+1,1+2,2$ +2 , and $3+1$ respectively, using the numbers and the symbols for these numbers. 
During a first training session, colony A was provided with 1 black circle and the symbol for 1 (' 1 ') near its sugar water tube, with 2 black circles and the symbol for 2 (' $Z$ ') near its meat food, and with a blank paper far from any reward. The ants were tested successively in front of 1 black circle and a blank paper, the symbol for 1 and a blank paper, 1 black circle and the symbol for 1, then in front of 2 black circles and a blank paper, the symbol for 2 and a blank paper, and the symbol for 2 and 2 black circles. During their second training period, they were moreover provided with twice 1 black circle and twice the symbol for 1 set aside their nest entrance. They were then tested faced with 1 black circle, 2 black circles and a blank paper, then faced with the symbol for 1, the symbol for 2 and a blank paper. During a first training session, colony B was provided with 1 black circle and the symbol for 1 near its sugar water tube, with 2 black circles and the symbol for 2 near the meat food, with 3 black circles and the symbol for 3 (' $]$ ') near pieces of thyme, and with a blank paper far from any reward. The ants were tested successively in front of 1 black circle and a blank paper, the symbol for 1 and a blank paper, 1 black circle and the symbol for 1 , then in front of 2 black circles and a blank paper, the symbol for 2 and a blank paper, the symbol for 2 and 2 black circles, and in front of 3 black circles and a blank paper, the symbol for 3 and a blank paper, and the symbol for 3 and 3 black circles. During their second training period, the ants were moreover provided with 1 black circle and 2 black circles, as well as with the symbol for 1 and that for 2 set aside their nest entrance. They were then tested faced with 1 black circle, 3 black circles and 2 black circles, then faced with the symbol for 1 , the symbol for 3 and that for 2. During a first training session, colony $\mathrm{C}$ was provided with 2 black circles and the symbol for 2 near its sugar water tube, with 4 black circles and the symbol for 4 (' 4 ') near its meat food, and with a blank paper far from any reward. The ants were tested successively in front of 2 black circles and a blank paper, the symbol for 2 and a blank paper, 2 black circles and the symbol for 2, then in front of 4 black circles and a blank paper, the symbol for 4 and a blank paper, and the symbol for 4 and 4 black circles. During their second training period, they were moreover provided with twice 2 black circles and twice the symbol for 2 set aside their nest entrance. They were then tested faced with 2 black circles, 4 black circles and 2 black circles, then faced with the symbol for 2 , the symbol for 4 , and the symbol for 2 . During a first training session, colony $\mathrm{D}$ was provided with 3 black circles and the symbol for 3 near its sugar water tube, with 1 black circle and the symbol for 1 near the meat food, with 4 black circles and the symbol for 4 near pieces of thyme, and with a blank paper far from any reward. The ants were tested successively in front of 3 black circles and a blank paper, the symbol for 3 and a blank paper, 3 black circles and the symbol for 3, then in front of 1 black circle and a blank paper, the symbol for 1 and a blank paper, the symbol for 1 and 1 black circle, and in front of 4 black circles and a blank paper, the symbol for 4 and a blank paper, the symbol for 4 and 4 black circles. During their second training period, the ants were moreover provided with 3 black circles and 1 black circle, as well as with the symbols for 3 and for 1 set aside their nest entrance. They were then tested faced with 3 black circles, 4 black circles and 1 black circle, and then faced with the symbol for 3 , the symbol for 4 and that for 1 .

\section{Results}

Numerical and statistical results are detailed in Table 1; photos are shown in Figure 3.

\subsection{Learning and Use of Symbol for 1 and for 2 to Make the Addition $1+1=2$ (Colony A)}

While being trained to one black circle and the symbol for 1 as well as to the symbol for 2 and two black circles versus a blank paper, the ants of colony A were meanly 13.8 in foraging all around the six presented cues. They had thus the opportunity of memorizing them and their location.

Tested in front of 1 black circle and a blank paper, the ants went essentially to the black circle: $72 \%$ of 50 ants did so, a proportion statistically significant $(\mathrm{P}=0.031)$. In front of the symbol for 1 and a blank paper, $72.1 \%$ of 68 ants went to the symbol, a result also significant $(\mathrm{P}=0.031)$. Confronted to a black circle and the symbol for 1 , the ants equally approached the two cues $(\mathrm{P}=0.625)$. The ants have thus duly associated the symbol 1 with the amount 1 .

Tested in front of 2 black circles and a blank paper, $70.9 \%$ of 55 ants approached the 2 circles. The difference between the ants' responses to the two scores was significant $(\mathrm{P}=0.031)$. When confronted to the symbol for 2 and to a blank paper, the tested ants reacted essentially to the symbol, $72.7 \%$ of their responses were for this cue. The difference of reaction to the two cues was significant $(\mathrm{P}=0.031)$. Faced with the symbol for 2 and 2 black circles, the ants went equally to these two cues $(\mathrm{P}=0.625)$. The ants have thus duly learned the association between the symbol for 2 and the amount 2 .

During their training to a pair of 1 circle set aside one another and two symbols for 1 also set aside one another, the ants were meanly 13.6 in the vicinity of these cues, what allowed them seeing and memorizing the cues.

In the presence of 1 black circle, 2 black circles and a blank paper, the tested ants reacted mostly to the 2 circles: $61.7 \%$ of their responses were for this cue. The difference between the ants' reaction to the 2 circles and to the 1 circle, as well as to the blank paper was significant $(\mathrm{P}=0.031)$. The difference between the ants' reaction to the 1 
circle and the blank paper was not $(\mathrm{P}=0.500)$. Confronted to the symbol for 1 , the symbol for 2 and a blank paper, the ants approached mostly the symbol for $2: 67.3 \%$ of their responses were for this cue. The difference between the ants' reaction to the symbol for 2 and to the symbol for 1 , as well as to the blank paper was significant $(\mathrm{P}=$ 0.031). The difference between the ants' reaction to the symbol for 1 and the blank paper was also significant $(\mathrm{P}=$ 0.031) what was not the case for the ants' reaction to the 1 circle and the blank paper (see here above). Consequently, the ants duly reacted to the correct symbol for 2 , but also significantly approached the 'wrong' symbol for 1 . They correctly made the addition (symbol for $1+\operatorname{symbol}$ for $1=\operatorname{symbol}$ for 2 ).

\subsection{Learning and Use of Symbols for 1, 2 and 3 for Making the Addition $1+2=3$ (Colony B)}

The ants of colony B were trained to 1 black circle and a symbol for 1 , to 2 black circles and a symbol for 2 , and to 3 black circles and a symbol for 3, versus a blank paper. During this training, they were meanly 9.6 in walking or staying in the vicinity of the different presented cues, being thus able to see and memorize them.

Tested in front of 1 black circle and a blank paper, the ants approached essentially the black circle: $76.5 \%$ of their responses were for this cue, a significant result $(\mathrm{P}=0.031)$. Confronted to the symbol for 1 and a blank paper, the tested ants reacted far mostly to the symbol: $82.9 \%$ of their responses were for this cue, a significant result $(\mathrm{P}=$ 0.031). Faced with the symbol for 1 and 1 black circle, the tested ants equally went to these two cues (NS). The ants have duly learned to associate the symbol for 1 with the amount 1 , responding similarly to these two elements.

Faced with 2 black circles and a blank paper, $78.1 \%$ of the ants' visits were for the 2 circles, a significant proportion $(\mathrm{P}=0.031)$. Confronted to the symbol for 2 and a blank paper, the ants were more numerous near the symbol than near the blank paper. Indeed, the proportions of responses for these cues equaled $78.0 \%$ and $22.0 \%$, the difference being significant $(\mathrm{P}=0.031)$. When tested in front of the symbol for 2 and 2 black circles, the ants approached similarly the two presented cues, with no statistical difference between their responses (NS). Consequently, even if they had already learned the association between the symbol for 1 and 1 element, the ants learned the association between the symbol for 2 and 2 elements (i.e. they reacted in the same way to these two last cues).

Confronted to 3 black circles and a blank paper, the tested ants reacted mostly to the 3 circles, with $71.9 \%$ of their response to this cue, a significant result $(\mathrm{P}=0.031)$. Faced with the symbol for 3 and a blank paper, the tested ants visited essentially the symbol, the proportion of responses to this cue equaling $72.9 \%$, what is significant $(\mathrm{P}=$ 0.031). In presence of the symbol for 3 and 3 black circles, the ants approached nearly equally the two cues: $48.1 \%$ ones approached the symbol and 51.4\% approached the 3 circles, the difference being not significant $(\mathrm{P}=0.626)$. Consequently, even if they had already learned the association between the amounts 1 and 2 and their respective symbols, the ants also learned the association between the amount 3 and its symbol: they reacted in the same way to these two cues.

During their training to 1 circle and 2 circles set aside one another and to the symbol for 1 and the symbol for 2 also set aside one another, the ants were meanly 9.8 all around these four cues at any time. They could thus saw and memorize them.

Tested in front of 1, 2 and 3 black circles, the ants mostly visited the 3 circles, with $73.2 \%$ response for this cue. The differences between the ants' response to the 3 circles and to the 1 circle, as well as to the 2 circles were significant $(\mathrm{P}=0.031)$. The difference between the ants' response to the 1 and the 2 circles was at the limit of significance $(\mathrm{P}=0.063)$. Confronted to the symbol for 1 , to that for 2 and to that for 3 , the ants approached essentially the symbol for 3 , with $65.6 \%$ response to this cue. The differences in reaction to the symbol for 3 and the symbol for 1 as well as for 2 were significant $(\mathrm{P}=0.031)$. The difference in reaction to the symbol for 1 and the symbol for 2 was not $(\mathrm{P}=0.313)$. The ants thus duly responded to the 3 circles (= the sum of 1 and 2 circles), and to the symbol for 3 (= the sum of the symbol for 1 and the symbol for 2).

\subsection{Learning and Use of Symbols for 2 and 4 for Making the Addition $2+2=4$ (Colony C)}

During their training, the ants of colony $\mathrm{C}$ were meanly 12.2 in walking or staying in the vicinity of the different presented cues, which they could thus see and memorize.

When tested in front of 2 black circles and a blank paper, the ants went mostly towards the circles: $80.9 \%$ of their responses were for this cue, a significant result $(\mathrm{P}=0.031)$. Tested in front of the symbol for 2 and a blank paper, the ants also went mostly to the symbol: $72.5 \%$ of their responses were for this cue, again, a significant result $(\mathrm{P}=$ 0.031 ). Faced with the 2 black circles and the symbol for 2 , the tested ants went nearly equally to the two cues, their responses equaling $48.3 \%$ and $51.7 \%$, with no statistical difference between these two scores (NS). The ants duly associated the symbol for 2 and the amount 2 since they reacted similarly to these two elements.

Tested in the presence of 4 black circles and a blank paper, the ants of colony $C$ visited essentially the 4 circles: the proportion of their responses to this cue equaled $80.6 \%$, what was significant $(\mathrm{P}=0.031)$. In the presence of the 
symbol for 4 and a blank paper, $74.6 \%$ of the responses were for the symbol, what was also significant $(\mathrm{P}=0.031)$. Confronted to the symbol for 4 and 4 black circles, the ants reacted equally to the two cues, with no statistical difference between the numbers of ants counted near each cue $(P=0.750)$. Consequently, even if they already learned the association between a symbol for 2 and the amount 2 , the ants, at the same time, learned the association between a symbol for 4 and the amount 4 (i.e. they reacted in the same way to these two elements).

During their training to twice 2 black circles and twice the symbol for 2 set near their nest entrance, the ants of colony $\mathrm{C}$ were meanly 13.9 in moving or staying in the vicinity of these four cues.

Tested in front of twice 2 black circles and one set of 4 black circles, the ants approached more the 4 black circles than the 2 ones: $67.9 \%$ of their responses were for this cue. The ants' response to the 4 circles statistically differed from their responses to each of the two 2 circles $(\mathrm{P}=0.031, \mathrm{P}=0.031)$, and their responses to the 2 circles placed at the left and at the right did not differ $(\mathrm{P}=0.188)$. The ants have thus duly perceived that 2 circles plus 2 circles (these two cues being set aside one another during training) equaled 4 circles. They behaved similarly in the presence of the symbols: they reacted more to the symbol for 4 (67.6\% of their responses) than to each of the two symbols for 2 . The difference between the response to the symbol for 4 and the responses to the two symbols for 2 was significant $(\mathrm{P}=$ $0.031, \mathrm{P}=0.031)$, that between the responses to the two symbols for 2 was not $(\mathrm{P}=0.125)$. The ants thus duly interpreted that two symbols for 2 (set side by side during training) were worth to one symbol for 4 .

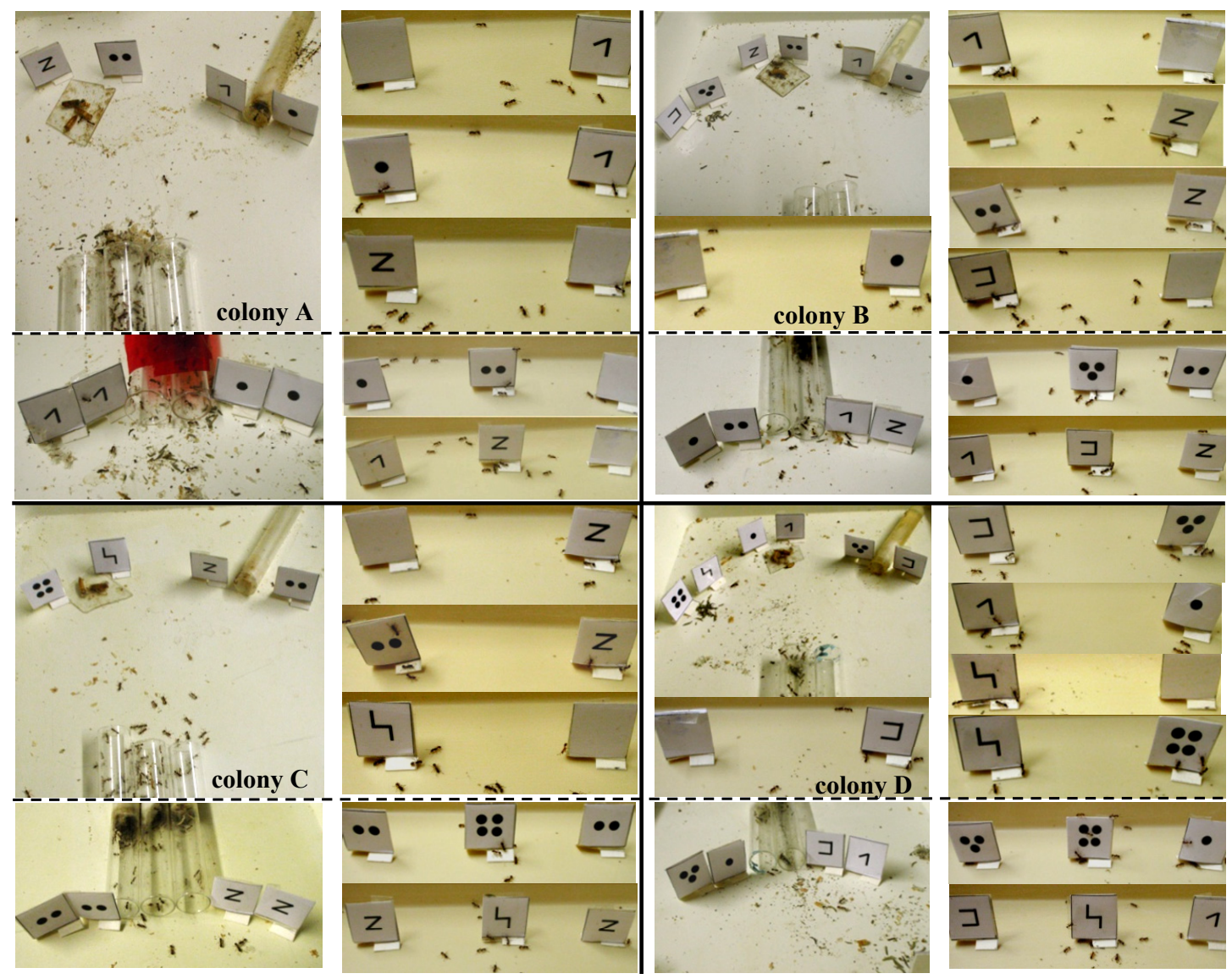

Figure 3. Some photos of the experiments made to learn numerical symbols to ants, then to examine if they could use the learned symbols for adding numbers

In a first step (photos on the left above the dotted line), the ants were trained to numbers of elements and to their corresponding symbols placed near a reward, and tested for checking their learning (photos on the right and above the dotted line). In a second step (photos on the left below the dotted line), the ants were provided near their nest entrance with two numbers of elements as well as with the two corresponding symbols, each time placed side by side and expected to be added up. It was then checked if the ants correctly added up the numbers and their symbols (photos on the right below the dotted line). Schemas of the experimental design and of the cues are given in Figures 1 and 2 . 
Table 1. Responses of ants trained to associate amounts to corresponding symbols, then to add these amounts or their symbols

\begin{tabular}{|c|c|c|c|c|c|c|c|c|c|c|c|}
\hline \multirow{2}{*}{$\begin{array}{l}\text { Colonies } \\
\text { cues }\end{array}$} & & \multirow{2}{*}{\multicolumn{3}{|c|}{$\mathrm{N}^{\circ}$ of ants near the cues }} & \multirow{2}{*}{\multicolumn{4}{|c|}{$\begin{array}{c}\mathrm{N}^{\circ} \text { of ants chronologically } \\
\text { summed by four }\end{array}$}} & \multicolumn{3}{|c|}{ Wilcoxon test } \\
\hline & & & & & & & & & $\mathrm{N}$ & $\mathrm{T}$ & $P$ \\
\hline \multicolumn{12}{|l|}{$\overline{\mathbf{A}}$} \\
\hline 1 circle & vs 0 circle & $36(72.0 \%)$ & vs & $14(28.0 \%)$ & $8,7,8,7,6$ & & $v s$ & $3,4,2,4,1$ & 5 & 15 & 0.031 \\
\hline symbol 1 & vs 0 circle & $49(72.1 \%)$ & $v s$ & $19(27.9 \%)$ & $14,8,12,9,6$ & & vs & $3,4,5,4,3$ & 5 & 15 & 0.031 \\
\hline symbol 1 & vs 1 circle & $32(50.0 \%)$ & vs & $32(50.0 \%)$ & $5,7,8,7,5$ & & vs & $5,6,10,7,4$ & 3 & 3 & 0.625 \\
\hline 2 circles & vs 0 circle & $39(70.9 \%)$ & vs & $16(29.1 \%)$ & $6,8,9,8,8$ & & vs & $1,4,4,3,4$ & 5 & 15 & 0.031 \\
\hline symbol 2 & vs 0 circle & $40(72.7 \%)$ & vs & $15(27.3 \%)$ & $8,8,11,6,7$ & & $v s$ & $2,4,4,2,3$ & 5 & 15 & 0.031 \\
\hline symbol 2 & vs 2 circles & $34(50.7 \%)$ & vs & $35(49.3 \%)$ & $4,8,6,8,8$ & & $v s$ & $7,8,5,7,8$ & 3 & 3 & 0.625 \\
\hline \multirow[t]{2}{*}{1 vs 2} & vs 0 circles & $11(18.3 \%)$ & ) $v s 37(61.7 \%) v$ & vs $12(20.0 \%)$ & $1,2,3,2,3$ & $v s$ & $5,7,10,7,8$ & vs $2,2,1,2,5$ & 5 & 15 & 0.031 \\
\hline & & & & & $1,2,3,2,3$ & & vs & $2,2,1,2,5$ & 3 & 3.5 & 0.500 \\
\hline \multirow[t]{2}{*}{ symbols 1} & 1 vs 2 vs 0 & $15(28.8 \%)$ & ) $v s 35(67.3 \%) v$ & $v s 2(3.8 \%)$ & $3,4,4,0,4$ & vs & $9,9,5,6,6$ & vs $\quad 1,0,0,0,1$ & 5 & 15 & 0.031 \\
\hline & & & & & $3,4,4,0,4$ & & vs & $1,0,0,0,1$ & 5 & 15 & 0.031 \\
\hline \multicolumn{12}{|l|}{ B } \\
\hline 1 circle & vs 0 circle & $39(76.5 \%)$ & $v s$ & $12(23.5 \%)$ & $7,7,6,10,9$ & & $v s$ & $1,2,4,2,3$ & 5 & 15 & 0.031 \\
\hline symbol 1 & vs 0 circle & $34(82.9 \%)$ & vs & $7(17.1 \%)$ & $9,6,8,6,5$ & & vs & $1,1,3,1,1$ & 5 & 15 & 0.031 \\
\hline symbol 1 & vs 1 circle & $25(49.0 \%)$ & vs & $26(51.0 \%)$ & $4,3,4,6,8$ & & vs & $4,3,4,6,9$ & 1 & - & NS \\
\hline 2 circles & vs 0 circle & $25(78.1 \%)$ & vs & $7(21.9 \%)$ & $4,5,6,5,5$ & & vs & $1,1,2,2,1$ & 5 & 15 & 0.031 \\
\hline symbol 2 & vs 0 circle & $32(78.0 \%)$ & vs & $9(22.0 \%)$ & $8,6,6,7,5$ & & $v s$ & $0,1,4,3,1$ & 5 & 15 & 0.031 \\
\hline symbol 2 & vs 2 circles & $41(48.2 \%)$ & $v s$ & $44(51.8 \%)$ & $5,10,9,11,6$ & & vs & $5,10,11,12,6$ & 2 & - & NS \\
\hline 3 circles & vs 0 circle & $46(71.9 \%)$ & vs & $18(28.1 \%)$ & $12,9,6,12,7$ & & vs & $0,2,5,7,4$ & 5 & 15 & 0.031 \\
\hline symbol 3 & vs 0 circle & $62(72.9 \%)$ & vs & $23(27.1 \%)$ & $12,12,13,1$ & 1,14 & $v s$ & $2,5,6,5,5$ & 5 & 15 & 0.031 \\
\hline symbol 3 & vs 3 circles & $34(48.6 \%)$ & vs & $36(51.4 \%)$ & $6,4,5,8,11$ & & $v s$ & $7,6,5,7,11$ & 3 & 4.5 & 0.626 \\
\hline \multirow[t]{2}{*}{1 vs 3} & vs 2 circles & $4(7.1 \%)$ & $v s 41(73.2 \%) v$ & $v S 11(19.6 \%)$ & $0,2,0,0,2$ & vs 7 & $7,8,11,8,7$ & vs $2,1,2,2,4$ & 5 & 15 & 0.031 \\
\hline & & & & & $0,2,0,0,2$ & & $v s$ & $2,1,2,2,4$ & 5 & 14 & 0.063 \\
\hline \multirow[t]{2}{*}{ symbols 1} & $1 v s 3 v s 2$ & $8(13.1 \%)$ & vs $40(65.6 \%) v$ & $v s \quad 13(21.3 \%)$ & $1,2,5,0,0$ & $v s$ & $5,7,9,11,8$ & vs $\quad 0,3,2,5,3$ & 5 & 15 & 0.031 \\
\hline & & & & & $1,2,5,0,0$ & & $v s$ & $0,3,2,5,3$ & 5 & 10 & 0.313 \\
\hline \multicolumn{12}{|l|}{ C } \\
\hline 2 circles & vs 0 circle & $38(80.9 \%)$ & $v s$ & $9(19.1 \%)$ & $5,4,9,12,8$ & & $v s$ & $0,0,3,4,2$ & 5 & 15 & 0.031 \\
\hline symbol 2 & vs 0 circle & $50(72.5 \%)$ & $v s$ & $19(27.5 \%)$ & $12,10,9,10$ & & $v s$ & $4,4,4,4,3$ & 5 & 15 & 0.031 \\
\hline symbol 2 & vs 2 circles & $29(48.3 \%)$ & $v s$ & $31(51.7 \%)$ & $6,7,7,4,5$ & & $v s$ & $6,7,7,5,6$ & 2 & - & NS \\
\hline 4 circles & vs 0 circle & $29(80.6 \%)$ & $v s$ & $7(19.4 \%)$ & $4,6,5,6,8$ & & $v s$ & $0,1,2,2,2$ & 5 & 15 & 0.031 \\
\hline symbol 4 & vs 0 circle & $44(74.6 \%)$ & $v s$ & $15(25.4 \%)$ & $6,6,8,12,12$ & & vs & $0,2,3,5,5$ & 5 & 15 & 0.031 \\
\hline symbol 4 & vs 4 circles & $43(50.0 \%)$ & vs & $43(50.0 \%)$ & $6,13,9,9,6$ & & vs & $5,10,9,9,10$ & 3 & 4 & 0.75 \\
\hline \multirow[t]{2}{*}{2} & vs 2 circles & $7(13.2 \%)$ & vs $36(67.9 \%) v$ & vs $10(18.9 \%)$ & $2,1,0,3,1$ & $v s$ & $8,6,5,9,8$ & $v s \quad 2,2,2,2,2$ & 5 & 15 & 0.031 \\
\hline & & & & & $2,1,0,3,1$ & & $v s$ & $2,2,2,2,2$ & 4 & 8 & 0.188 \\
\hline \multirow[t]{2}{*}{ symbols 2} & $2 v \mathrm{~s} 4 v \mathrm{~s} 2$ & $9(13.2 \%)$ & $v s 46(67.6 \%) v$ & $v s \quad 13(19.1 \%)$ & $2,1,3,2,1$ & vs 1 & $11,9,8,9,9$ & vs $3,3,3,2,2$ & 5 & 15 & 0.031 \\
\hline & & & & & $2,1,3,2,1$ & & vs & $3,3,3,2,2$ & 3 & 6 & 0.125 \\
\hline \multicolumn{12}{|c|}{ 年, } \\
\hline 3 circles & vs 0 circle & $35(74.5 \%)$ & vs & $12(25.5 \%)$ & $8,6,6,7,8$ & & vs & $2,3,1,3,3$ & 5 & 15 & 0.031 \\
\hline symbol 3 & vs 0 circle & $45(80.4 \%)$ & vs & $11(19.6 \%)$ & $11,8,9,6,11$ & & $v s$ & $3,0,2,3,3$ & 5 & 15 & 0.031 \\
\hline symbol 3 & vs 3 circles & $40(48.2 \%)$ & vs & $43(51.8 \%)$ & $8,8,4,6,14$ & & vs & $8,8,6,6,15$ & 2 & - & NS \\
\hline 1 circle & vs 0 circle & $49(71.0 \%)$ & vs & $20(29.0 \%)$ & $6,6,11,11,1$ & & $v s$ & $1,3,5,4,7$ & 5 & 15 & 0.031 \\
\hline symbol 1 & vs 0 circle & $58(78.4 \%)$ & $v s$ & $16(21.6 \%)$ & $12,15,13,9$ & & vs & $2,7,4,0,3$ & 5 & 15 & 0.031 \\
\hline symbol 1 & vs 1 circle & $30(50.8 \%)$ & vs & $29(49.2 \%)$ & $5,6,8,6,5$ & & vs & $5,7,7,6,4$ & 3 & 4 & 0.75 \\
\hline 4 circles & vs 0 circle & $53(81.5 \%)$ & vs & $12(18.5 \%)$ & $6,9,15,12,1$ & & vs & $2,2,2,4,2$ & 5 & 15 & 0.031 \\
\hline symbol 4 & $v s \quad 0$ circle & $55(82.1 \%)$ & vs & $12(17.9 \%)$ & $12,12,11,1$ & & $v s$ & $2,2,2,3,3$ & 5 & 15 & 0.031 \\
\hline symbol 4 & vs 4 circles & $32(48.5 \%)$ & $v s$ & $34(51.5 \%)$ & $5,5,5,6,10$ & & $v s$ & $5,4,5,8,12$ & 3 & 4.5 & 0.626 \\
\hline \multirow{2}{*}{\multicolumn{2}{|c|}{3 vs 4 vs 1 circles }} & $20(14.1 \%)$ & ) $v s 7(61.3) v$ & vs $35(24.6 \%)$ & $0,4,5,5,6 v$ & is 15 & $21,19,22,11$ & 0 vs $2,7,9,9,8$ & 5 & 15 & 0.031 \\
\hline & & & & & $0,4,5,5,6$ & & $v s$ & $2,7,9,9,8$ & 5 & 15 & 0.031 \\
\hline \multirow{2}{*}{\multicolumn{2}{|c|}{$\begin{array}{lllll}\text { symbols } 3 & \text { vs } & 4 & \text { vs } & 1\end{array}$}} & $6(6.7 \%)$ & vs $75(83.3 \%)$ & vs $9(10.0 \%)$ & $1,0,2,1,2 v s$ & 12,1 & $13,19,14,17$ & 7 vs $0,1,4,3,1$ & 5 & 15 & 0.031 \\
\hline & & & & & $1,0,2,1,2$ & & $v s$ & $0,1,4,3,1$ & 5 & 11 & 0.219 \\
\hline
\end{tabular}

Details are given in the text and photos are shown in Figure 3. The ants could associate the presented symbols and corresponding amounts, and could make the suggested additions using the amounts as well as the symbols. 


\subsection{Learning and Use of Symbols for 3 and 1 for Making the Addition $3+1=4$ (Colony D)}

During their training to the eight presented cues, the ants of colony D were meanly 9.0 in foraging or resting in the vicinity of these cues which they could thus see and memorize.

Tested in the presence of 3 black circles and a blank paper, the ants went mostly to the 3 circles, with $74.5 \%$ of their responses being for this cue, a significant result $(\mathrm{P}=0.031)$. Faced with the symbol for 3 and a blank paper, the tested ants responded with a score of $80.4 \%$ to the symbol for 3 , also a significant result $(\mathrm{P}=0.031)$. In the presence of the symbol for 3 and 3 circles, the ants responded equally to the two cues, with $48.2 \%$ and $51.8 \%$ of responses for these two cues, the difference being of course not significant (NS). The ants reacted thus in the same way to the 3 circles and to its symbol; they duly associated these two elements.

In the presence of 1 black circle and a blank paper, the ants visited mostly the circle: $71 \%$ of their responses were for this cue, a significant result $(\mathrm{P}=0.031)$. In the presence of the symbol for 1 and a blank paper, the ants also visited mostly the symbol: $78.4 \%$ of their responses were for this cue, a significant result $(\mathrm{P}=0.031)$. Confronted to the symbol for 1 and 1 black circle, the ants approached equally the two cues, with no statistical difference between their responses to the two cues $(\mathrm{P}=0.750)$. The ants have thus perfectly perceived 1 circle and the symbol 1 as signifying the same notion, even if they also did so for the symbol for 3 and 3 circles.

Faced with 4 black circles and a blank paper, the tested ants reacted essentially to the circles: $81.5 \%$ of their responses were for this cue, a significant result $(\mathrm{P}=0.031)$. Faced with the symbol for 4 and a blank paper, $82.1 \%$ of the ants' responses were also for the symbol, a significant proportion $(\mathrm{P}=0.031)$. In the presence of the symbol for 4 and 4 black circles, the tested ants similarly reacted to the two cues $(\mathrm{P}=0.626)$.

While being trained to 3 and 1 black circles, as well as to the symbols for 3 and for 1, set at the nest entrance, meanly 8.9 ants were at any time moving or staying near these four cues. They could thus sufficiently perceive and potentially be able to add them up.

Tested in front of 3, 4, and 1 black circles, the ants visited essentially the 4 circles: $61.3 \%$ of their responses were for this cue. The ants' response to the 4 circles statistically differed from that to the 3 and to the 1 circles (each time: $\mathrm{P}=0.031)$, and the ants' response to the 3 and the 1 circles also statistically differed $(\mathrm{P}=0.031)$. The later difference may be due to the location of the 1 circle just aside the nest entrance (Figure 3, colony D). However, obviously, the ants of colony D duly perceived that 3 circles and 1 circle, all together, equaled 4 circles. In front of the symbols for 3 , for 4 and for 1 , the tested ants went essentially towards the symbol for $4: 83.3 \%$ of their responses were for this cue. The difference between the ants' responses to the symbol for 4 and to the symbol for 3 , as well as to the symbol for 1 was significant $(\mathrm{P}=0.031)$, while that between the responses to the symbol for 3 and to the symbol for 1 was not $(\mathrm{P}=0.219)$. The ants thus duly perceived that the symbol for 3 aside that for 1 equaled the symbol for 4 , and this addition seemed to be easier to make than the same one using numbers of circles. This ability in adding symbols is discussed in the following section.

\section{Discussion}

Knowing that workers of the ant $M$. sabuleti can add up numbers when seeing the solution during training, and can acquire multiple numerical symbolisms, we here examined whether these ants could add up using learned numeric symbols, an a priori complex task.

The ants were firstly trained in order to learn the required symbols, i.e. the association between the required numbers and symbols. This training lasted a rather long time since the ants were then tested day after day to check if they effectively acquired the correct numerical symbolisms. After that, they were provided with the symbols to add, presented side by side, as well as with, also set side by side, the corresponding numbers to add, all of them deposited just at the nest entrance, an inevitable place and a strong reward for the ants. At that time, the ants simply applied what they had previously acquired through operative conditioning (i.e. the meaning of the symbols) and used their ability to add two numerosities sighted side by side. The ants succeeded in adding up symbol $1+$ symbol $1=$ symbol 2 , symbol $1+\operatorname{symbol} 2=$ symbol 3 , symbol $2+\operatorname{symbol} 2=\operatorname{symbol} 4$, and symbol $3+$ symbol $1=$ symbol 4. This ability can be explained by the fact that the ants can apply in a subsequent situation what they have previously acquired through conditioning, a fact experimentally highlighted in Cammaerts \& Cammaerts (2018). The ants' a priori complex behavior of adding by means of symbols resulted thus from a strong (long lasting) conditioning, an appropriate location of the elements required for learning the task, an application of what they have learned during that conditioning, and their capability in adding amounts sighted simultaneously.

With an increasing number of elements, the use of symbols may even be easier for adding up than a precise counting of the elements (e.g. the present ants' score for symbol 4 as compared to that for 4 elements: Table 1, colony D). The use of a symbol may be also more rapid and not much influenced by changes in the characteristics 
(color, shape, size, location, etc.) of the elements to be counted. This ease of use is the expected benefit of symbolism. In humans, numerical symbols reach a high level of signification, a high semiotic value. According to Nieder (2009), humans' numerical competence passes from an iconic stage (each number of an increasing series is associated with a visual or vocal symbol, but the last symbol is not considered as being the sum of all the numbers of the series) to an indexical stage (this time, the last symbol associated to the last number of an increasing series is also considered as representing the sum of all the numbers), and finally to a symbolic stage (relations are established between the symbols which can be used according to meaningful rules). On the contrary, animals only reach an iconic level.

Let us recall a few studies which demonstrated that animals can use symbols for making simple arithmetic operations. Birds such as pigeons (Olthof et al., 2000) and parrots (Pepperberg, 2006a, 2012) have this ability, also observed in primates, such as macaques (Washburn \& Rumbaugh, 1991) and chimpanzees (Boysen \& Berntson, 1989; Biro \& Matsuzawa, 2001). Among the invertebrates, the honeybee has been shown to present this numerosity ability (Howard et al., 2019a, b) and the present work shows that ants have it also. This list may be potentially longer since, at our mind, the use of symbols is not a complex task but an easy one, a task simplifying the calculation of amounts, and therefore likely to be detained or acquired by many species. As a matter of fact, species living in groups or being social use visual, acoustical, olfactory and tactile signals to communicate. Each of these social signals can be considered as being a kind of symbol which has its own signification and usefulness and which generally induces reactions in congeners.

\section{References}

Addessi, E., Crescimbene, L., \& Visalberghi, E. (2008). Food and token quantity discrimination in capuchin monkeys (Cebus apella). Animal Cognition, 11: 275-282. doi:10.1007/s10071-007-0111-6

Agrillo, C., Dadda, M., Serena, G., \& Bisazza, A. (2008). Do fish count? Spontaneous discrimination of quantity in female mosquitofish. Animal Cognition, 11(3): 495-503. doi:10.1007/s10071-008-0140-9. PMID 18247068.

Agrillo, C., Dadda, M., Serena, G., \& Bisazza, A. (2009). Use of number by fish. PLoS ONE, 4(3): e4786. doi:10.1371/journal.pone.0004786

Beran, M.J. (2004). Long-term retention of the differential values of Arabic numerals by chimpanzees (Pan troglodytes). Animal Cognition, 7(2), 86-92. doi:10.1007/s10071-003-0191-x

Beran, M.J., Harris, E.H., Evans, T.A., Klein, E.D., Chan, B., Flemming, T.M., \& Washburn, D.A. (2008). Ordinal judgments of symbolic stimuli by capuchin monkeys (Cebus apella) and rhesus monkeys (Macaca mulatta): The effects of differential and nondifferential reward. Journal of Comparative Psychology, 122(1), 52-61. doi:10.1037/0735-7036.122.1.52

Biro, D., \& Matsuzawa, T. (2001). Use of numerical symbols by the chimpanzee (Pan troglodytes): cardinal, ordinals and the introduction of zero. Animal Cognition, 4: 193-199. doi:10.1007/s100710100086

Bortot, M., Agrillo, C., Avarguès-Weber, A., Bisazza, A., Miletto Petrazzini, M.E., \& Giurfa, M. (2019). Honeybees use absolute rather than relative numerosity in number discrimination. Biology Letters, 15, 20190138. http://dx.doi.org/10.1098/rsbl.2019.0138

Boysen, S.T., \& Berntson, G.G. (1989). Numerical competence in a chimpanzee (Pan troglodytes). Journal of Comparative Psychology, 103(1), 23-31. doi:10.1037/0735-7036.103.1.23

Brannon, E.M., \& Terrace, H.S. (1998). Ordering of the numerosities 1 to 9 by monkeys. Science, 282(5389): 746-749. doi:10.1126/science.282.5389.746.

Brannon, E.M., \& Terrace, H.S. (2000). Representation of the numerosities 1-9 by rhesus macaques (Macaca mulatta). Journal of Experimental Psychology: Animal Behavior Processes, 26(1): 31-49. doi:10.1037/0097-7403.26.1.31.

Brannon, E.M., Wusthoff, C.J., Gallistel, C.R., \& Gibbon, J. (2001). Numerical subtraction in the pigeon: Evidence for a linear subjective number scale. Psychological Science, 12(3): 238-243. doi:10.1111/1467-9280.00342

Cammaerts, M.-C. (2008). Visual discrimination of cues differing as for their number of elements, their shape or their orientation. Biologia, 63(6), 1169-1180. doi:10.2478/s11756-008-0172-2

Cammaerts, M.-C., \& Cammaerts, R. (2018). Can ants apply what they acquired through operant conditioning? International Journal of Biology, 10(4), 16-22. doi:10.5539/ijb.v10n4p16 
Cammaerts, M.-C., \& Cammaerts, R. (2019a). Ants' capability of adding numbers of identical elements. International Journal of Biology, 11(3), 25-36. doi:10.5539/ijb.v11n3p25

Cammaerts, M.-C., \& Cammaerts, R. (2019b). Ants fail to add numbers of same elements seen consecutively. International Journal of Biology, 11(3), 37-48. doi:10.5539/ijb.v11n3p37

Cammaerts, M.-C., \& Cammaerts, R. (2019c). Subtraction-like effect in an ant faced with numbers of elements which includes a crossed one. International Journal of Biology, 11(4), 51-66. doi:10.5539/ijb.v11n4p51

Cammaerts, M.-C., \& Cammaerts, R. (2020a). Influence of shape, color, size and relative position of elements on their counting by an ant. International Journal of Biology, 12(2), 26-40. doi:10.5539/ijb.v12n2p26

Cammaerts, M.-C., \& Cammaerts, R. (2020b). Ants can associate a symbol with a number of elements through conditioning. International Journal of Biology, 12(3), 1-13. doi:10.5539/ijb.v12n3p1

Cammaerts, M.-C. \& Cammaerts, R. (2020c). Ants can acquire multiple symbolisms. International Journal of Biology, 12(3), 18-26. doi:10.5539/ijb.v12n3p18

Cammaerts, R., \& Cammaerts, M.-C. (2020). Ants' mental positioning of amounts on a number line. International Journal of Biology, 12(1), 30-45. doi:10.5539/ijb.v12n1p30

Cantlon, J.F., \& Brannon, E.M. (2006). Shared system for ordering small and large numbers in monkeys and humans. Psychological Science, 17(5), 401-406. doi:10.1111/j.1467-9280.2006.01719.x

Carazo, P., Font, E, Forteza-Behrendt, E., \& Desfilis, E. (2009). Quantity discrimination in Tenebrio molitor: evidence of numerosity discrimination in an invertebrate? Animal Cognition, 12: 463-470. doi:10.1007/s10071-008-0207-7

Carazo P., Fernandez-Perea, R., \& Font, E. (2012). Quantity estimation based on numerical cues in the mealworm beetle (Tenebrio molitor). Frontiers in Psychology,3(502): 1-7 http://doi.org/10.3389/fpsyg.2012.00502

Cox, L., \& Montrose, V.T. (2015). Quantity discrimination in domestic rats, Rattus norvegicus. Animals, 6, 46. doi:10.3390/ani6080046

Cross, F.R., \& Jackson, R.R. (2017). Representation of different exact numbers of prey by a spider-eating predator. Interface Focus, 7: 20160035. doi:10.1098/rsfs.2016.0035

Dacke, M., Srinivasan (2008). Evidence for counting in insects. Animal Cognition, 11: $683-689$. doi:10.1007/s10071-008-0159-y

Diester, I., \& Nieder, A. (2007). Semantic associations between signs and numerical categories in the prefrontal cortex. PLos Biology, 5(11): e294. doi:10.1371/journal.pbio.0050294

Ditz, H. M., \& Nieder, A. (2016). Numerosity representations in crows obey the Weber-Fechner law. Proceedings of the Royal Society, B, 283: 20160083. doi:10.1098/rspb.2016.0083

Flombaum, J.I., Junge, J.A., \& Hauser, M.D. (2005). Rhesus monkeys (Macaca mulatta) spontaneously compute addition operations over large numbers. Cognition, 97: 315-325. doi:10.1016/j.cognition.2004.09.004

Garland, A., Low, J. (2014). Addition and subtraction in wild New Zealand robins. Behavioural Processes, 109 : 103-110. doi:10.1016/j.beproc.2014.08.022

Garland, A., Low, J., \& Burns, K.C. (2012). Large quantity discrimination by North Island robins (Petroica longipes). Animal Cognition, 15: 1129-1140. doi:10.1007/s10071-012-0537-3

Gazes, R.P., Diamond, R.F.L., Hope, J.M., Caillaud, D., Stoinski, T.S., \& Hampton, R.R. (2017). Spacial representation of magnitude in gorillas and orangutans. Cognition, 168, 312-319.https://dx. doi.org./10.1016/j.cognition.2017.07.010

Gelman, R., Gallistel, C.R. (1978). The child's understanding of number. Cambridge, Mass., Harvard University Press, Cambridge. www.hup.harvard.edu $>$ catalog

Gross, H.J., Pahl, M., Si, A., Zhu, H., Tautz, J., \& Zhang, S. (2009). Number-based visual generalisation in the honeybee. PLoS ONE, 4 (1), e4263. doi:10.1371/journal.pone.0004263

Hauser, M.D., MacNeilage, P., \& Ware, N. (1996). Numerical representations in primates. Proceedings of the National Academy of Sciences (USA), 93: 1514-1517. doi:10.1073/pnas.93.4.1514

Howard, S.R., Avarguès-Weber, A., Garcia, J.E., Greentree, A.D., \& Dyer, A.G. (2019a). Numerical cognition in honeybees enables addition and subtraction. Cognitive Neuroscience. 5, 1-6. http://advances.sciencemag.org/ 
Howard S.R., Avarguès-Weber, A., Garcia, J.E., Greentree, A.D., \& Dyer, A.G. (2019b). Achieving arithmetic learning in honeybees and examining how individuals learn. Communicative \& Integrative Biology, 12(1), 166-170. doi:10.1080/19420889.2019.1678452

Howard, S.R., Avarguès-Weber, A., Garcia, J.E., Greentree, A.D. \& Dyer, A.G. (2019c). Symbolic representation of numerosity by honeybees (Apis mellifera): matching characters to small quantities. Proceedings of the Royal Society B, 286, 20190238. doi:10.1098/rspb.2019.0238

Howard, S.R., Avarguès-Weber, A., Garcia, J.E., Greentree, A.D. \& Dyer, A.G. (2019d). Surpassing the subitizing threshold: appetitive-aversive conditioning improves discrimination of numerosities in honeybees. Journal of Experimental Biology, 222: jeb205658. doi:10.1242/jeb.205658

Howard, S.R., Schramme, J., Garcia, J.E., Ng, L., Avarguès-Weber, A., Greentree, A.D. \& Dyer, A.G. (2020). Spontaneous quantity discrimination of artificial flowers by foraging honeybees. Journal of Experimental Biology, 223: jeb223610. doi:10.1242/jeb.22310

Hunt, S., Low, J., \& Burns, K. (2008). Adaptive numerical competency in a food-hoarding songbird. Proceedings of the Royal Society, B, 275 (1649): 2373-2379. doi:10.1098/rspb.2008.0702. PMC 2603231.

Irie, N., Hiraiwa-Hasegawa, M., \& Kutsukake, N. (2019). Unique numerical competence of Asian elephants on the relative numerosity judgment task. Journal of Ethology, 37: 111-115. doi.org/10.1007/s10164-018-0563-y

Jordan, K.E., \& Brannon, E.M. (2006). Weber's law influences numerical representations in rhesus macaques (Macaca mulatta). Animal Cognition. 9, 159-172. doi:10.1007/s10071-006-0017-8

Krusche, P., Uller, C., \& Dicke, U. (2010). Quantity discrimination in salamanders. The Journal of Experimental Biology, 213: 1822-1828. doi:10.1242/jeb.039297

Matsuzawa, T. (1985). Use of numbers by a chimpanzee. Nature, 315(2): 57-59. doi:10.1038/315057a0

Matsuzawa, T. (2009). Symbolic representation of number in chimpanzees. Current Opinion in Neurobiology, 19: 92-98. www.sciencedirect.com

Murofushi, K. (1997). Numerical matching behavior by a chimpanzee (Pan troglodytes): Subitizing and analogue magnitude estimation. Japanese Psychological Research, 39(32), 140-153. doi:10.1111/1468-5884.00050

Nieder, A. (2009). Prefrontal cortex and the evolution of symbolic reference. Current Opinion in Neurobiology, 19(1), 99-108. doi:10.1016/j.conb.2009.04.008

Nieder, A., Freedman, D.J., \& Miller, E.K. (2002). Representation of the quantity of visual items in the primate prefrontal cortex. Science, 297, 1708-1711. www.sciencemag.org

Okuyama, S., Kuki, T., \& Mushiake, H. (2015). Representation of the numerosity 'zero' in the parietal cortex of the monkey. Scientific Reports, 5, 10059. https:// doi 10.1038/srep10059

Olthof, A., Iden, C.M., \& Roberts, W.A. (1997). Judgments of ordinality and summation of number symbols by squirrel monkeys (Saimiri sciureus). Animal Behavior Processes, 23(3), 325-339. doi.org/10.1037/0097-7403.23.3.325

Olthof, A, \& Roberts W.A. (2000). Summation of symbols by pigeons (Columba livia): the importance of number and mass of reward items. Journal of Comparative Psychology, 111 (2), 158-166. http://animalstudiesrepository.org/acwp_asie

Pepperberg, I.M. (2006a). Grey parrot (Psittacus erithacus) numerical abilities: Addition and further experiments on a zero-like concept. Journal of Comparative Psychology, 120(1): 1-11. doi:10.1037/0735-7036.120.1.1

Pepperberg, I.M. (2006b). Ordinality and inferential abilities of a grey parrot (Psittacus erithacus). Journal of Comparative Psychology, 120(3), 205-216. doi:10.1037/0735-7036.120.3.205

Pepperberg, I.M. (2012). Further evidence for addition and numerical competence by a grey parrot (Psittacus erithacus). Animal Cognition, 15(4): 711-717. doi 10.1007/s10071-012-0470-5

Range, F., Jenikejew, J., Schröder, I., \& Virányi, Z. (2014). Difference in quantity discrimination in dogs and wolves. Frontiers in Psychology, 5: 1299. doi:10.3389/fpsyg.2014.01299. PMC 4235270. PMID 25477834.

Rodríguez, R.L., Briceño, R.D., Briceño-Aguilar, E., \& Höbel, G. (2015). Nephila clavipes spiders (Araneae: Nephilidae) keep track of captures prey counts: testing for a sense of numerosity in an orb-weaver. Animal Cognition. 18(1), 307-314. doi:10.1007/s10071-014-0801-9. Epub 2014 Aug 28. 
Rose G.J. (2017). The numerical abilities of anurans and their neural correlates: insights from neuroethological studies of acoustic communication. Philosophical Transactions of the Royal Society, B: Biological Sciences, 373: 20160512. http://doi.org/10.1098/rstb.2016.0512

Rugani, R, Fontanari, L., Simoni, E., Regolin, L., \& Vallortigara, G. (2009). Arithmetic in newborn chicks. Proceedings of the Royal Society, B, 276: 2451-2460. http://doi.org/10.1098/rspb.2009.0044

Rumbaugh, D.M., Savage-Rumbauch, S., \& Hegel, M.T. (1987). Summation in the chimpanzee (Pan troglodytes). Journal of Experimental Psychology: Animal and Behaviour Processes, 13(2): 107-115. PMID: 3572305

Stancher, G., Sovrano, V.A., Potrich, D, \& Vallortigara, G. (2013). Discrimination of small quantities by fish (redtail splitfin, Xenotoca eiseni). Animal Cognition, 16: 307-312. doi:10.1007/s10071-012-0590-y

Stancher, G., Rugani, R., Regolin, L., \& Vallortigara, G. (2015). Numerical discrimination by frogs (Bombina orientalis). Animal Cognition, 18: 219-229. doi:10.1007/s10071-014-0791-7

Siegel, S., \& Castellan, N.J. (1988). Nonparametric statistics for the behavioural sciences. Singapore, McGraw-Hill Book Company. https:/www.amazon.com/Sidney-Siegel...Statistics.../B008WDIR6

Tomonaga, M. (2006). Relative numerosity discrimination by chimpanzees (Pan troglodytes): evidence for approximate numerical representations. Animal Cognition. 11: 43-57. doi:10.1007/s10071-007-0089-0

Tornick, J.K., Callahan, E.S., \& Gibson, B.M. (2015). An investigation of quantity discrimination in Clark's nutcrackers (Nucifraga columbiana). Journal of Comparative Psychology, 129(1): 17-25. doi:10.1037/a0037863

Uller, C., Jaeger, R, Guidry, G., \& Martin, C. (2003). Salamanders (Plethodon cinereus) go for more: rudiments of number in an amphibian. Animal Cognition, 6: 105-112. doi:10.1007/s10071-003-0167-x

Washburn, D.A., \& Rumbauch, D.M. (1991). Ordinal judgments of numerical symbols by macaques (Macaca mulatta). Psychological Science, 2(3), 190-193. doi:10.1111/j.1467-9280.1991.tb00130.x

West, R.E, \& Young, R.J. (2002). Do domestic dogs show any evidence of being able to count? Animal Cognition, 5: 183-186. doi:1001007/s10071-002-0140-0

Xia, L., Siemann, M., \& Delius J. D. (2000). Matching of numerical symbols with number of responses by pigeons. Animal Cognition. 3, 35-43. doi:10.1007/s100710050048

\section{Copyrights}

Copyright for this article is retained by the author(s), with first publication rights granted to the journal.

This is an open-access article distributed under the terms and conditions of the Creative Commons Attribution license (http://creativecommons.org/licenses/by/4.0/). 